Revista de Comunicación y Salud. 2022, Vol. 12, 1-20

Editado por Cátedra de Comunicación y Salud

ISSN: 2173-1675

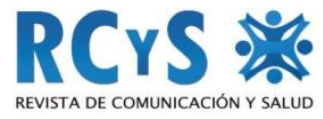

Enviado 27/05/2021

Aprobado 14/06/2021

Publicado 03/01/2022

\title{
ESTRATEGIAS PERSUASIVAS Y EMOCIONALES EN LAS CAMPAÑAS AUDIOVISUALES DE LA DGT EN EL PERIODO 2011-2019
}

\section{Persuasive and emotional strategies in the DGT's audiovisual campaigns in the period 2011-2019}

\author{
Iulia Mihaela Marinescu \\ Universidad Complutense de Madrid. España. \\ iuliamar@ucm.es \\ Guillermo Mejías Martínez \\ Universidad Complutense de Madrid. España. \\ gmejias@ucm.es \\ Antonia Isabel Nogales-Bocio \\ Universidad de Zaragoza. España. \\ anogales@unizar.es
}

\section{Cómo citar el artículo}

Mihaela Marinescu, I., Mejías Martínez, G. y Nogales-Bocio, A. I. (2022). Estrategias persuasivas y emocionales en las campañas audiovisuales de la DGT en el periodo 2011-2019. Revista de Comunicación y Salud, 12, 1-20. https://doi.org/10.35669/rcys.2022.12.e286

\section{Resumen}

La publicidad institucional de la Dirección General de Tráfico ha cobrado cada vez más fuerza en los últimos años. La tarea histórica de la entidad de disminuir la siniestralidad vial y por consiguiente la mortalidad en accidentes de tráfico constituye un gran reto en la actualidad. Este trabajo se plantea con el fin de extraer una serie de resultados y conclusiones cuantitativas y cualitativas atendiendo a las características y dimensiones del discurso audiovisual que la DGT ha mantenido en sus campañas en el periodo 20112019. La acotación temporal responde al periodo de vigencia del segundo Plan Estratégico de Seguridad Vial (2011-2020) que sienta las bases de la actuación de la 
DGT y supone la hoja de ruta en su misión de disminuir la siniestralidad vial. Específicamente se trata de averiguar cuáles son los factores emocionales y persuasivos que encierran estas campañas y cómo se manifiestan, cuáles son los soportes y mensajes utilizados y qué impacto o alcance tienen en el público espectador. Los resultados muestran que en el discurso audiovisual de la DGT a lo largo de la recopilación de las 74 piezas audiovisuales del periodo 2011-2019 predomina una línea negativa que apuesta por campañas de alto impacto emocional a través de mecanismos de persuasión efectivos.

Palabras clave: Publicidad institucional, emociones, persuasión, spot, audiovisual, DGT.

\begin{abstract}
The institutional advertising of the Dirección General de Tráfico has gained more and more strength in recent years. The entity's historical task of reducing road accidents and, consequently, mortality in traffic accidents is a great challenge at present. This work is proposed with the aim of extracting a series of quantitative and qualitative results and conclusions based on the characteristics and dimensions of the audiovisual discourse that the DGT has maintained in its campaigns in the period 2011-2019. The time frame corresponds to the period of validity of the second Plan Estratégico de Seguridad Vial (2011-2020), which lays the foundations for the DGT's actions and is the roadmap for its mission to reduce road accidents. Specifically, the aim is to find out what are the emotional and persuasive factors involved in these campaigns and how they are manifested, what are the supports and messages used and what impact or scope they have on the viewing public. The results show that in the audiovisual discourse of the DGT throughout the compilation of the 74 audiovisual pieces of the period 2011-2019 there is a predominance of a negative line that bets on campaigns with a high emotional impact through effective persuasive mechanisms.
\end{abstract}

Keywords: Institutional advertising, emotions, persuasion, spot, audiovisual, DGT.

\title{
1. INTRODUCCIÓN
}

"Que todos lleguemos sanos y salvos a casa todas las noches" (DGT, 2018). Con esta frase la Dirección General de Tráfico resume su misión y su compromiso con la sociedad. En sus 50 años de funcionamiento, la publicidad institucional de la entidad ha cobrado una enorme importancia social en su lucha por disminuir la siniestralidad vial y, por consiguiente, la mortalidad en las carrete-ras españolas. El enorme volumen de campañas que la DGT realiza desde 1960 se centra en varios ejes comunicativos a través de diferentes perspectivas y soportes. A lo largo de los años la DGT ha ido endureciendo sus mensajes publicitarios. La dimensión emocional y persuasiva ha cobrado una fuerza enorme, siempre con el fin de realizar una labor didáctica y de concienciación en la ciudadanía. 
Estrategias persuasivas y emocionales en las campañas audiovisuales de la DGT en el periodo 2011-2019

El Plan Estratégico de Seguridad Vial (2011-2020) ha sentado las bases de la labor comunicadora de la entidad estableciendo las pautas para una convivencia positiva en cuanto al uso de las vías públicas se refiere. En el presente trabajo se analizará la publicidad institucional que la Dirección General de Tráfico ha llevado a cabo entre 2011 y 2019. La acotación temporal responde al periodo de vigencia del segundo Plan Estratégico de Seguridad Vial (2011-2020) que sienta las bases de la actuación de la DGT y supone la hoja de ruta en su misión de disminuir la siniestralidad vial. Para la realización de la investigación se hará una recopilación de todas las piezas en formato audiovisual que la Dirección General de Tráfico ha lanzado entre 2011 y 2019, ambos inclusive. Esta acotación temporal responde a la necesidad de realizar un análisis en un tiempo actual o relativamente cercano para que su abordaje resulte de mayor interés.

Este trabajo se plantea pues con el fin de extraer una serie de resultados y conclusiones cuantitativas y cualitativas atendiendo a las características y dimensiones del discurso audiovisual que la DGT mantiene en sus campañas entre 2011 y 2019. Específicamente se trata de averiguar cuáles son los factores emocionales y persuasivos que encierran estas campañas y cómo se manifiestan, cuáles son los soportes y mensajes utilizados y qué impacto o alcance tienen en el público espectador.

Las hipótesis de partida que se manejan en la presente investigación son dos:

H1. Las campañas audiovisuales correspondientes al Plan Estratégico de Seguridad Vial (2011-2020) han experimentado un cambio radical en cuanto a los elementos emocionales y persuasivos que encierran tanto desde el punto de vista de la imagen como en su planteamiento narrativo.

H2. Las campañas encierran fuertes valores sociales como la importancia de la vida, los vínculos familiares y sociales, la prudencia o la responsabilidad por la vida de terceros, entre otros. Todos estos valores funcionan como aprendizaje social y apelan a las emociones primarias del individuo.

\subsection{Marco referencial}

La publicidad puede entenderse como un mecanismo de producción de signos, imágenes y mensajes que adquieren sentido en las relaciones semióticas que conforman. Pero su engranaje no funciona de la misma manera y no está creado para unas mismas finalidades: es aquí donde radica la diferencia.

Cada uno de los investigadores en la materia han propuesto sus definiciones del término a lo largo del tiempo. El concepto de publicidad ha sufrido múltiples interpretaciones y no siempre ha sido entendido de la misma manera. Por ejemplo, Cortés González (2008) afirma:

Publicidad es toda forma de comunicación realizada por una persona física o jurídica, pública o privada, en el ejercicio de una actividad comercial, industrial, artesanal o profesional, con el fin de pro-mover de forma directa o indirecta la

Revista de Comunicación y Salud. 2022, Vol. 12, 1-20 
Estrategias persuasivas y emocionales en las campañas audiovisuales de la DGT en el periodo 2011-2019

contratación de bienes muebles o inmuebles, servicios, derechos y obligaciones (Ley 34/1988 General de Publicidad citado en Cortés González, 2008, p. 228).

Esta definición muestra una visión diferente de la publicidad, que vista desde la actualidad resultan parciales y no responden a la complejidad del término. Benavides (1997) afirma que el discurso publicitario es uno de los mejores ejemplos de cómo los discursos sociales se desarrollan y proyectan en la vida de los sujetos, grupos e instituciones. Y es que ese es el impacto que los mensajes publicitarios tiene sobre el individuo a través del texto y la imagen que porta. El discurso publicitario está funcionando en la sociedad después del acto de visualización, y es capaz de crear diferentes respuestas sensoriales en el receptor, como sensaciones o recuerdos. Por lo tanto, el discurso publicitario está íntimamente ligado a la ética y a la responsabilidad social a la hora de crear mensajes publicitarios, es más, la dimensión de la publicidad se puede entender como un hecho social por su indudable capacidad de provocar ciertos efectos en las personas.

\subsubsection{Publicidad institucional. Aproximación teórica y tipología}

La publicidad institucional debe ser entendida como un fenómeno diferenciado de la publicidad comercial ya que no comparten las mismas características ni finalidades. Según Benavides (1997) la publicidad institucional es un elemento educativo y socializador en el marco de la sociedad actual. Las administraciones públicas hacen uso de ella para implantar en la sociedad los valores que debe ejercer y compartir.

A priori este tipo de campañas tienen la aceptación ética de la sociedad ya que intentan corregir problemas sociales globales. Así pues, en la publicidad institucional se desarrollan campañas de comunicación de diversa índole específicamente por los gobiernos e instituciones públicas, así como por empresas u organismos que de ellas dependen. La publicidad institucional se convierte así en un mecanismo fundamental en la relación que los organismos públicos mantienen con los ciudadanos y por extensión con los diversos grupos sociales existentes en la esfera pública. El mensaje publicitario que se deriva -que no es una simple circulación de mensajes pagados- contribuye a la construcción de la realidad simbólica y cultural de la sociedad.

En este sentido, Cortés González va más allá del concepto de publicidad "como aquel proceso de comunicación para divulgar bienes o servicios y propiciar las transacciones económicas que deben realizar los consumidores para conseguirlas" (Cortés Gonzáles, 2008 , p. 223). El autor se centra en los mensajes que indican cuáles son las preocupaciones, los intereses y los objetivos de la sociedad. En definitiva, este tipo de mensajes publicitarios intentan buscar vías para solventar los problemas sociales, siempre de la mano con políticas específicas que respalden estas técnicas publicitarias.

Según Pineda Cachero y Rey (2009), "la perspectiva de la publicidad institucional como promotora de los intereses generales no debe conducir a una percepción teórica funcionalista ni excesiva-mente beatífica, de la comunicación del Estado". Para los autores el impulso propagandístico y manipulador coexiste en la comunicación 
Estrategias persuasivas y emocionales en las campañas audiovisuales de la DGT en el periodo 2011-2019

institucional. A diferencia de las percepciones anteriores, la publicidad institucional no es solo un esfuerzo educativo orientado a la mejora de las relaciones sociales de los ciudadanos, sino que puede ser una oportunidad para que los individuos y clases que controlen el Estado intenten dominar el pensamiento y las conductas de la ciudadanía. Siguiendo con este planteamiento se propone una publicidad institucional como práctica de comunicación desde el conjunto de la sociedad y no para el conjunto de la sociedad. Esta visión no solo alejaría esta forma de publicidad de la propaganda, sino que abriría la comunicación del Estado a procesos de cambio social desde la base de la población. Más allá de las múltiples visiones, no cabe duda de que la publicidad institucional tiene la suficiente entidad para consolidarse como un fenómeno central en las sociedades contemporáneas y para ser estudiada de forma independiente de la publicidad comercial y convencional. Este instrumento tiene objetivos muy diferentes respecto a la publicidad comercial, aunque compartan los espacios y los tiempos y posiblemente una similar estructura discursiva.

\subsubsection{La publicidad social como vertiente de la publicidad institucional}

Existe una gran variedad temática de la publicidad institucional, aunque algunos autores como García López (2001) se refieren a ella como publicidad social. Otros autores como Alvarado López (2010) estudian la publicidad social como un instrumento esencial a la hora de transmitir de-terminados contenidos al servicio de la sociedad. La autora empieza con esta cita, que abre su amplio análisis sobre la publicidad social:

Howard Gossage, el rebelde más clarividente de todos los publicitarios afirmaba que la publicidad es un instrumento demasiado valioso para malgastarlo en los productos comerciales y que sólo está justificada cuando se usa con fines sociales (David Ogilyvy citado en Alvarado López, 2010, p. 75).

Siguiendo esta línea, la publicidad social es "aquella cuyos objetivos propiamente publicitarios son sociales, y sirven a una entidad cuya finalidad última o razón de ser es también social, $y$, por lo tanto, exenta de otros intereses políticos o comerciales" (Alvarado López, 2010, p. 78). Las campañas sociales responden a la necesidad de comunicar de forma masiva y persuasiva un determinado mensaje a una audiencia establecida a priori, denominado por la autora como "el blanco del mensaje".

Los temas sociales tienen mucha más presencia en la sociedad, pero no siempre estas encuentran su hueco en una publicidad social pura y fiel a sus principios. Cada vez más temáticas y leguajes propios de la publicidad social se trasladan a la publicidad con fines corporativos y comerciales, atravesando así la línea ideológica que la define. De esta manera se produce un panorama confuso, ante el cual la autora ve necesario distinguir "bajo la superficie de los mensajes los objetivos concretos de estos, los fines de la entidad emisora y las causas sociales a las que responden" (Feliu Albaladejo, 2009).

En cuanto a esta frontera difusa, Moragas (2005) también se pronuncia. La enorme importancia económica que han adquirido las campañas institucionales centra la

Revista de Comunicación y Salud. 2022, Vol. 12, 1-20 
Estrategias persuasivas y emocionales en las campañas audiovisuales de la DGT en el periodo 2011-2019

atención en el control y el destino de estas inversiones, más allá del debate ideológico y cultural, relativo a sus contenidos. Para revisar su misión en la sociedad y las funciones del servicio público de información se debe llevar a cabo un control de los contenidos y la transparencia de sus campañas. Hay que definir cuáles son las prioridades de la intervención pública frente a las nuevas necesidades informativas de la sociedad moderna.

\subsubsection{La persuasión en la publicidad}

Según Segura García (2017), la publicidad está conformada por dos tipos de estrategias argumentativas: la dimensión informativa y la dimensión persuasiva basada en la apelación de la sensibilidad y emociones para lograr un cambio en la conducta. Estas dos dimensiones fundamentales cumplen con los tres objetivos observados por la Retórica Clásica: docere (información), delectare (entretenimiento) y movere (persuasión final) (Segura García, 2017, p. 69). El proceso de persuasión se basa en los dos últimos, por este motivo la publicidad centra su intención en torno a movere, ya que está comprobado que las emociones y la motivación son fuerzas que impactan de manera directa en el comportamiento del ser humano (López Vázquez, 2007). El mensaje persuasivo se sirve de distintos recursos para alcanzar sus objetivos. (López Eire citado en Segura García, 2010, p.65) señala que, a través de un efectivo mensaje retórico se crean valores y actitudes que a su vez se integran en la esfera de los valores sociales colectivos. En este sentido la publicidad bebe de la Retórica con el fin de construir un lenguaje adecuado, conciso y estético. El objetivo final es el de transmitir mensajes claros e impactantes. Sin embargo, no hay que confundir Retórica con el concepto de Publicidad. A pesar de coincidir en esencia, existen notables diferencias entre el discurso publicitario y el discurso retórico clásico, que radica los fines, lenguaje múltiple, carácter unilateral y una orientación hacia el receptor masivo, consumidor de productos o susceptible de un cambio de actitud. Los medios y la estructura del mensaje también difieren entre Publicidad y Retórica. La primera hace uso de las tecnologías más avanzadas, incluyendo imágenes 0 el movimiento. Estos elementos no fueron contemplados por la Retórica tradicional, que supone un cambio cualitativo respecto al clásico modelo. En definitiva, la esencia de la publicidad depende de las intenciones del anunciante o del publicista y que su fin último no es el engaño, sino el sentido ético de su existencia.

\subsubsection{Plan Estratégico de Seguridad Vial (2011-2020)}

Naciones Unidas designó la década 2011-2020 como la "Década de la Acción para la Seguridad Vial" (DGT, s.f.). Esta década reta a todos los países suscriptores a disminuir un $50 \%$ el número de fallecidos en el mundo para 2020. Con el nombre inicial de Jefatura Central de Tráfico, la ahora denominada Dirección General de Tráfico se fundó en 1959 con el objetivo de responder a las necesidades sociales en materia de transporte. La entidad trabaja por el logro de este reto a través del segundo Plan Estratégico de Seguridad Vial 2011-2020, que además de otras muchas actuaciones, apuesta por un mecanismo de comunicación muy potente. La DGT en cada uno de sus informes anales de siniestralidad recoge su avance en la consecución de estos logros.

Revista de Comunicación y Salud. 2022, Vol. 12, 1-20 
Estrategias persuasivas y emocionales en las campañas audiovisuales de la DGT en el periodo 2011-2019

"Informar e involucrar a la sociedad en su responsabilidad con la mejora de la seguridad vial" (Dirección General de Tráfico, 2011, p. 147). Esta es la premisa de la entidad en su Plan Estratégico de Seguridad Vial que abarca el periodo de tiempo 2011-2020. El Plan fue aprobado el 25 de febrero de 2011 por el Consejo de Ministros, tras la aprobación por el Consejo de Superior de Seguridad Vial en su sesión plenaria de 23 de noviembre de 2010.

Entre otras muchas áreas de actuación del segundo Plan Estratégico -mejora de las infraestructuras, renovación del parque de vehículos-, la política de seguridad vial apuesta por seguir actuando en la "modificación del comportamiento de los usuarios principalmente a través de sus campañas de comunicación. (Dirección General de Tráfico, 2011, p.5). El objetivo es que los usuarios de la vía desarrollen conductas responsables de forma voluntaria y para ellos la DGT apuesta por una mejora en el ámbito de la comunicación. Este plan centra su comunicación en una serie de ejes temáticos clave: alcohol, drogas, velocidad, distracciones y sistemas de seguridad (. Asimismo, establece los distintos perfiles de receptores para los cuales el mensaje publicitario se adapta de forma cuidada y adecuada. En cuanto a la edad, el plan recoge todos los espectros dando visibilidad tanto a niños, jóvenes, adultos o mayores. En cuanto a los tipos de usuarios el plan atiende a conductores, ciclistas y motoristas como objetivos principales. Los peatones y otros usuarios de la vía publica también se contemplan en las distintas estrategias de actuación.

\subsubsection{Emociones y persuasión en las campañas DGT: aproximación general}

Los estudios que se han realizado acerca del discurso audiovisual de la DGT están recogidos en pocas investigaciones y bastante actuales. Trabajos de interés son: Uso y Eficacia del Miedo como Factor Persuasivo en las Campañas Institucionales de la Dirección General de Tráfico (2014) de Crisbel Vieira Gracia; Eficacia de la publicidad emocional y racional: análisis de las campañas de la Dirección General de Tráfico (20152016) de Ylenia Gómez García; Música y emociones en las Campañas Institucionales: el caso de la DGT española (2011) de Estrella Martínez Rodrigo y Rosario Segura García. Los mecanismos emocionales cada vez más utilizados por el mundo de la publicidad son en la actualidad un tema de interés en la investigación de las ciencias sociales, especialmente en lo referente a los efectos que estas prácticas pueden tener sobre el receptor. Distintos investigadores del tema, como Segura García (2017) y Vieira Gracia (2014) coinciden en la importancia de la exploración de la dimensión emocional que la DGT ha desarrollado en gran par-te de sus campañas institucionales. En su determinación por lograr los mayores efectos sobre el espectador y disminuir el nivel de siniestralidad de las carreteras españolas, la DGT opta por este tipo de publicidad buscando siempre un cambio en la mentalidad del público y consecuentemente un cambio de conducta. Los primeros pasos que una campaña de estas características debe cumplir son: ser creíbles y mostrar una realidad con la que el espectador se pueda identificar, utilizar mecanismos de convicción apelando a las emociones primarias del ser humano y a los argumentos, provocar reflexión para que el mensaje perdure en el tiempo y tenga un efecto en las conductas y lograr que el receptor del mensaje lo transmita a su vez a terceros.

Revista de Comunicación y Salud. 2022, Vol. 12, 1-20 
Frente a los mensajes racionales, el discurso emocional de la entidad se basa en el impulso y la fascinación para conseguir en el receptor una directa asociación de ideas agradables o desagradables. Una de esas ideas desagradables que la DGT de forma recurrente en sus campañas es la muerte. Más allá de la carga persuasiva que se puede encontrar en los mensajes emocionales, su efectividad se basa en el criterio analítico y cognitivo del que recibe el mensaje.

\section{METODOLOGÍA}

Para tener una perspectiva general de las campañas audiovisuales que la Dirección General de Tráfico ha lanzado entre 2011 y 2019 se ha realizado un exhaustivo rastreo con el fin de recopilar la totalidad de las piezas audiovisuales. La clasificación de tipo cuantitativo responde al periodo anual general. Dentro de cada año se incluyen todas las campañas, pero la exactitud de las fechas de lanzamiento no se ha podido clarificar de forma exacta.

Mediante tablas organizadas en orden cronológico se hará un análisis cuantitativo y cualitativo de la totalidad de las piezas que han sido seleccionadas cuidadosamente de distintas fuentes. En este primer análisis se atenderá a aspectos cuantitativos como número y duración y a aspectos cualitativos en cuanto a temáticas y características generales que se desarrollarán en el apartado correspondiente. La fuente principal para la recopilación de las piezas individuales es la Mediateca Oficial de la Dirección General de Tráfico. En el proceso de recopilación se han tenido en cuenta en primer lugar criterios cronológicos -clasificando las distintas piezas en función de su correspondiente año-. También se han aplicado criterios de selección (separando las piezas audiovisuales de las cuñas radiofónicas), que se encuentran almacenadas en el mismo sitio web. Para la verificación de la totalidad de las piezas recopiladas, además del proceso de cribado de la Mediateca General de Tráfico se han cotejado otras fuentes como la página de YouTube de la Dirección General de Tráfico y la página de YouTube del Ministerio de Interior, con el fin de obtener el número completo de piezas audiovisuales y completar información para el análisis posterior.

Al final del proceso de selección y localización de las campañas se ha procedido a la elaboración de una tabla de clasificación que incluyen el total de las piezas audiovisuales que la Dirección General de Tráfico ha realizado y lanzado. Este análisis muestra una sucesión de piezas audiovisuales como unidades de análisis independiente, aunque algunas de ellas compartan características, frases o rasgos temáticos comunes. Por lo tanto, al hablar de campaña audiovisual en ninguno de los caos se refiere a un conjunto de piezas audiovisuales, sino que cada una es objeto de análisis individual. Para la recopilación de las piezas tampoco se ha tenido en cuenta los canales de difusión, y aunque la mayoría de las piezas han sido emitidas en espacios de la televisión pública, otras han visto la luz a través de distintas plataformas ajenas a la televisión como, por ejemplo, la página de YouTube del Ministerio de Interior y otras plataformas y redes sociales. 
La clasificación que se muestra a continuación, así como el orden en el que se plasman las piezas, responde a un criterio de análisis y procesamiento de la información propios, inspirado por otras investigaciones específicas de Vieira Gracia (2014), Gómez García (2014-2015) y Segura García (2017). De estos autores se han extraído criterios de análisis recurrentes en todos ellos. El análisis cuantitativo y cualitativo atiende a: pieza audiovisual, representatividad (línea positiva o línea negativa), línea temática, duración, nivel de persuasión (intencionalidad explicita de persuadir al espectador) y presencia de imágenes violetas explícitas/implícitas.

\section{RESULTADOS}

El primer resultado es que a lo largo de los 9 años analizados se han lanzado un total de 74 piezas audiovisuales (Tabla 1), cuyos resultados se muestran en los gráficos 1, 2, 3 y 4 . Atendiendo a la clasificación cronológica de las piezas audiovisuales, la primera conclusión es que la entidad mantiene un comportamiento irregular en el lanzamiento de sus campañas. Así, el número de piezas audiovisuales lanzadas por año varían de forma considerable. Si en los años 2011, 2012, 2013 y 2014 el número de lanzamientos se mantiene similar, oscilando entre las 9 y 12 piezas, el número de spots lanzados en los años 2015 y 2016 se reduce considerablemente a 4 y 3 piezas. Es en el año 2017 cuando se produce un repunte del número de lanzamientos, llegando de nuevo a 11. La media anual aproximada que resulta de esta recopilación es de 8 campañas por año. En el año 2018 se produce un descenso hasta las 5 piezas que contrasta con las 10 piezas del año 2019.

La duración de las piezas audiovisuales analizadas varía en función de la temática y las características que presentan. La duración de los productos oscila entre los 11 segundos como duración mínima y los 4:41 minutos como duración máxima (de forma puntual), en ningún caso superando este límite. A modo general la duración que presentan la mayoría de los anuncios es de un minuto o inferior. Los anuncios más cortos en general están cargados de mayor dramatismo, mientras que las piezas de carácter más informativo e instruccional tienen mayor duración, no superando los cinco minutos. Dentro de esta conclusión general existen excepciones. 


\section{Estrategias persuasivas y emocionales en las campañas audiovisuales de la DGT en el periodo 2011-2019}

Tabla 1. Piezas audiovisuales de la DGT del periodo 2011-2019 analizadas

\begin{tabular}{|c|c|}
\hline$\tilde{\text { ño }}^{\mathbf{A}}$ & Piezas audiovisuales \\
\hline $011^{2}$ & $\begin{array}{l}\text { Gracias } \\
\text { Disfruta del camino, pero hazlo de forma segura } \\
\text { No importa cómo te desplaces, lo que queremos es que llegues } \\
\text { No importa a qué hora vas o vienes, lo que queremos es que llegues } \\
\text { No importa de dónde vienes ni adónde vas, lo que queremos es que llegues } \\
\text { No importa si vas a trabajar o a descansar, lo que queremos es que llegues } \\
\text { Algún día los accidentes serán cosas del pasado } \\
\text { Los tiempos cambian, peor el mensaje permanece. Si bebes no conduzcas } \\
\text { ¿Cómo usar el limitador de velocidad? } \\
\text { Me apunto a la conducción inteligente } \\
\text { Me apunto a moverme en bici } \\
\text { Señales reflectantes V-23 }\end{array}$ \\
\hline 012 & $\begin{array}{l}\text { A tu lado vamos todos } \\
\text { El club de los } 15 \\
\text { Los motoristas pueden disfrutar de la moto y seguir disfrutando de su vida } \\
\text { De casa al trabajo y del trabajo a casa I } \\
\text { De casa al trabajo y del trabajo a casa II } \\
\text { El coche oficina por Leo Harlem } \\
\text { No sin mi GPS por Leo Harlem } \\
\text { El peatón electrónico por Leo Harlem } \\
\text { SI sabes cómo acaba por qué empezar }\end{array}$ \\
\hline 013 & $\begin{array}{l}\text { No puedes vivir sin él. Ley de Newton I } \\
\text { No puedes vivir sin él. Ley de Newton II } \\
\text { No conduzcas bajo sus efectos } \\
\text { El verano está lleno de vida y de vidas, respétalas } \\
\text { Lo mejor de este verano hubiese sido poder contarlo. Viajar es vivir } \\
\text { Excursionistas y peatones. No pongas tu vida en peligro } \\
\text { Si vas en moto siempre con casco } \\
\text { Disfruta del verano con bici, pero siempre con casco } \\
\text { El futuro viaja en bici } \\
\text { Da el paso, anda } \\
\text { En Navidad más que nunca queremos estar a tu lado }\end{array}$ \\
\hline $\begin{array}{r}2 \\
014\end{array}$ & $\begin{array}{l}\text { El síndrome del carril izquierdo, problema cerebral } \\
\text { No esperes que nadie adivine tus movimientos, usa los intermitentes } \\
\text { Tu trabajo más urgente es seguir vivo } \\
\text { Consejos para evitar accidentes de furgonetas y camiones } \\
\text { Manejar cosas que pueden matar exige toda tu concentración } \\
\text { Gracias por hacer tu parte, gracias por llegar } \\
\text { Saca tus drogas de la circulación } \\
\text { A veces la convivencia es cuestión de vida o muerte } \\
\text { Te dejo mi moto, una acción de conductor a conductor }\end{array}$ \\
\hline $\begin{array}{r}2 \\
015\end{array}$ & $\begin{array}{l}\text { Muévete con conciencia } \\
\text { El porro más caro del mundo } \\
\text { La canción más cara del mundo } \\
\text { Las gafas de sol más caras del mundo }\end{array}$ \\
\hline 016 & $\begin{array}{l}\text { ¿Sabes lo que es un } 2 \% \text { ? } \\
\text { El trayecto de tu vida. De Ana a doctora Ana Sánchez } \\
\text { El trayecto de tu vida. De Carlos a Carlos, papá de Isabel }\end{array}$ \\
\hline $\begin{array}{r}2 \\
017 \\
\end{array}$ & $\begin{array}{l}\text { Historias al volante, La noticia } \\
\text { Historias al volante. El encuentro }\end{array}$ \\
\hline
\end{tabular}




\begin{tabular}{|c|c|}
\hline & $\begin{array}{l}\text { Music. Tú sabes hacerlo, al volante pasa del móvil } \\
\text { Magia, Si miras la carretera de vez en cuando solo ves la carretera de vez en cuando } \\
\text { Un aspecto clave, la seguridad } \\
\text { Testimonios que pueden salvar: Anna } \\
\text { Testimonios que pueden salvar: Mar } \\
\text { Testimonios que pueden salvar: Jordi } \\
58 \text { Almas Ciclistas } \\
\text { Al volante no uses el móvil } \\
360^{\circ} \text { Tú Eliges }\end{array}$ \\
\hline $\begin{array}{r}2 \\
018\end{array}$ & $\begin{array}{l}\text { El hombre de cristal } \\
\text { Distracciones: vivo } \\
\text { Distracciones: muerto } \\
\text { Reenámorate de tu coche } \\
\text { Creencias absurdas }\end{array}$ \\
\hline $\begin{array}{r}2 \\
019\end{array}$ & $\begin{array}{l}\text { Cómo llegar } \\
\text { El hospital } \\
\text { La cárcel } \\
\text { El cementerio } \\
\text { Gracias } \\
\text { Velocidad en convencionales } \\
14 \text { metros de nada son una gran diferencia } \\
\text { A } 90 \mathrm{~km} / \mathrm{h} \text {, como en Europa } \\
\text { El efecto túnel } \\
\text { Aplastante }\end{array}$ \\
\hline
\end{tabular}

Fuente: Elaboración propia

Las 74 piezas audiovisuales recopiladas presentan distintas características y temáticas que responden al criterio básico de la publicidad institucional: transmitir a la sociedad una serie de valores sociales, humanos y de convivencia, así como influir o modificar su comportamiento. Estos valores sociales, humanos y de convivencia llaman a la responsabilidad y a la concienciación social sobre una problemática global y muy presente en la sociedad del siglo XXI, como es el de la siniestralidad vial y todas sus consecuencias tanto a nivel personal como social. Las campañas analizadas responden de forma fiel a las dos líneas de actuación fundamentales que engloba el segundo Plan Estratégico de Seguridad Vial (2011-2020) en su amplio apartado de comunicación: informar y concienciar al público en su condición de usuarios de la vía pública e implicar a la sociedad civil en el desarrollo positivo y eficaz de iniciativas que ayuden a una convivencia.

Atendiendo a la clasificación temática (Gráfico 1), se cumplen los objetivos del Plan Estratégico de Seguridad Vial (2011-2020). Se cubren las principales líneas temáticas recogidas en el plan: alcohol, drogas, velocidad, distracciones y sistemas de seguridad. Los ejes temáticos que más se repiten son Alcohol, Drogas y Distracciones al volante. Este tratamiento informativo responde a las causas más graves de accidentes por lo que es entendible que estas tres problemáticas aparezcan con más frecuencia en sus campañas audiovisuales. Existe una tendencia general a mostrar de forma directa los efectos de estos tres factores ya sea mostrando imágenes explícitas de los accidentes y de las víctimas o terminar las acciones en fondo negro o blanco, sugiriendo de forma implícita la producción del accidente, acentuándose en los últimos años. 


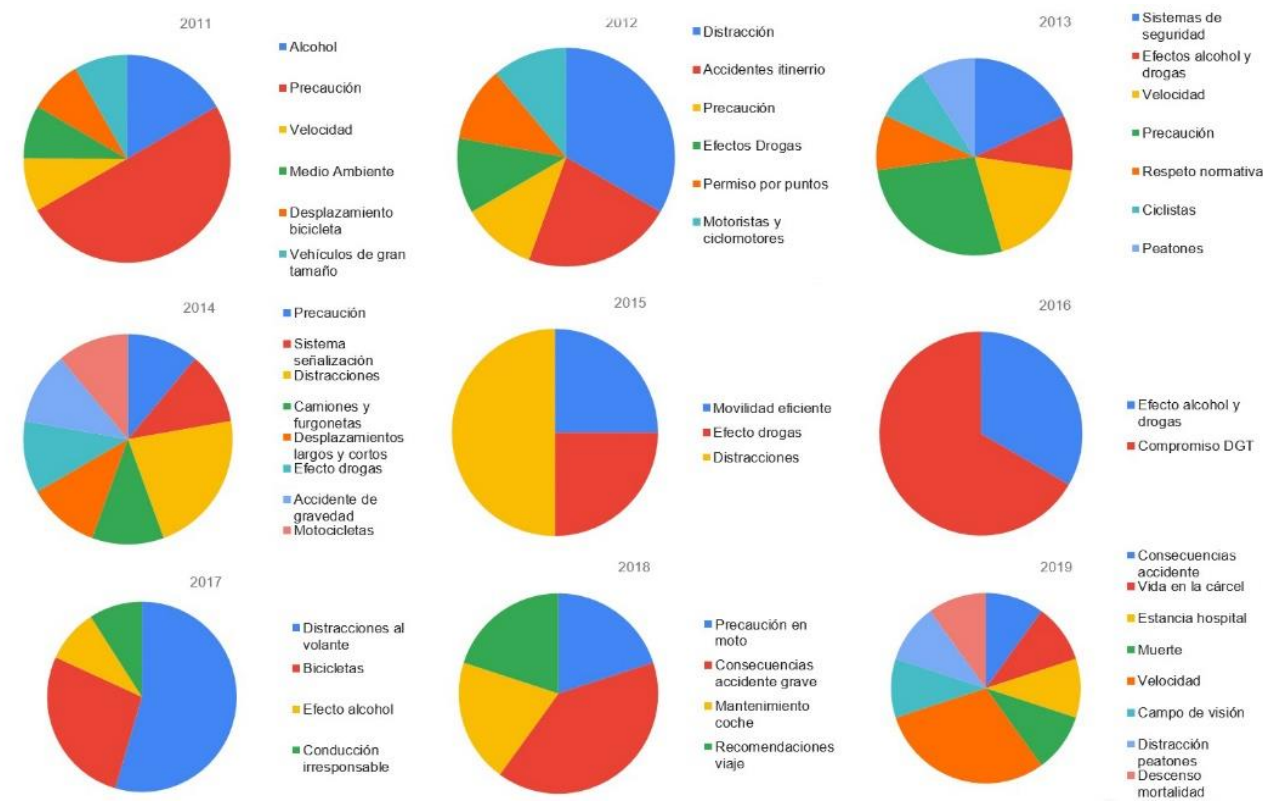

Gráfico 1. Líneas temáticas de las diferentes piezas audiovisuales de la DGT en el periodo 2011-2019

Fuente: Elaboración propia

Si bien es cierto que todas encierran ciertos valores según sus objetivos, se pueden distinguir dos modalidades o caracteres distintos. Por un lado, están las campañas de carácter positivo, que aluden a la conducción responsable gracias a la cual se evitan situaciones de accidentes y sufrimiento y se muestra el disfrute, la llegada al destino y los beneficios de una conducción responsable (Gráfico 2). Esta línea predomina en los años 2011, 2012 y 2013. Por otro lado, están las campañas de carácter negativo, en las cuales se muestran los efectos directos o indirectos de una conducción irresponsable por parte de los conductores o de terceros. Esta línea es la predominante y la mayoría de las piezas contienen gran dramatismo, con imágenes explícitas o implícitas y de gran impacto emocional. Este carácter se acentúa en los años 2015, 2017-2019. 

el periodo 2011-2019

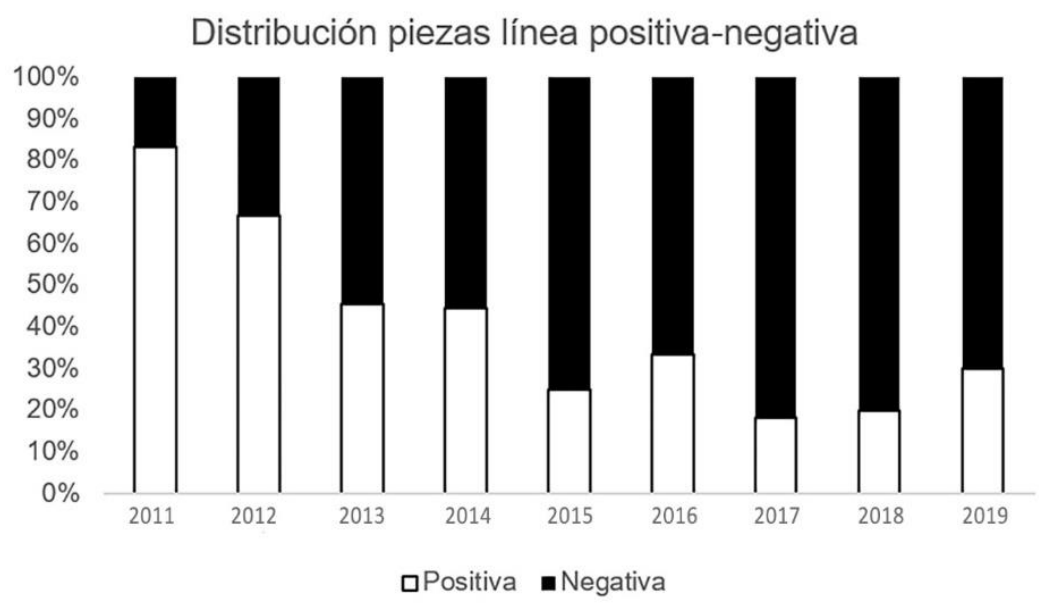

Gráfico 2. Distribución línea positiva o negativa piezas audiovisuales de la DGT en el periodo 2011-2019

Fuente: Elaboración propia

A nivel general, las campañas de corte negativo son más abundantes que las de corte positivo. Si en el año 2011 y 2012 predomina la perspectiva positiva, es ya a partir de 2013 cuando se detecta un cambio radical del discurso de la DGT, apostando por un mayor realismo y dramatismo. En los puntos posteriores se destacarán los diferentes matices de estas. La mayoría de las piezas audiovisuales de línea negativa presentan un alto impacto emocional mientras que por lo general las campañas de corte positivo suelen contener un impacto emocional leve o inexistente.

La Dirección General de Tráfico cubre todos los perfiles de receptores que constan en el Plan Estratégico de Seguridad Vial (2011-2020), poniendo el foco sobre los usuarios de automóviles, motocicletas y ciclomotores, bicicletas y peatones. Este amplio espectro de destinatarios hace que tenga una cobertura equilibrada, responsable y eficaz, aunque el mayor peso de las campañas se centra en los conductores de automóviles y motocicletas. Se detecta un tratamiento equilibrado en cuanto al género, dando visibilidad tanto a los conductores como a las conductoras en la mayoría de las campañas, aunque en los últimos años se observa una mayor presencia del conductor masculino en el protagonismo de las campañas. En cuanto a espectros de edad, los menores también tienen visibilidad, generalmente como víctimas de las imprudencias de los adultos.

En cuanto a los aspectos de impacto emocional, se aprecia una evolución de la línea racional, predominante en 2011, que con el transcurso de los años adopta una perspectiva más emocional. Así, se produce una acentuación de campañas que paulatinamente adquieren un mayor dramatismo, tanto desde el punto de vista narrativo como visual. Por ejemplo, si en el año 2011 predominan campañas de tipo racional e informativo, al ir avanzando en el tiempo se observa que, en los años 2014-2019 predominan campañas de gran impacto emocional con imágenes violentas explícitas. Es el caso de "Ley de Newton" (2014), "El porro más caro del mundo" (2015) o "Magia" (2017). 
Estrategias persuasivas y emocionales en las campañas audiovisuales de la DGT en el periodo 2011-2019

Respecto a factores emocionales, sentimientos o sensaciones que se pueden detectar en los anuncios, a nivel general se perciben dos vertientes diferentes en función de la línea positiva o negativa de la campaña, mencionada anteriormente. Los sentimientos de alegría, felicidad, optimismo, ilusión, diversión, agradecimiento, compromiso y responsabilidad son recurrentes en las campañas de corte positivo. Por el contrario, en los anuncios de corte negativo predominan emociones y sentimientos primarios del ser humano como miedo, angustia, estado de shock, sorpresa, vulnerabilidad, arrepentimiento, soledad, tristeza, dolor, pérdida y vacío, entre otras. Es destacable cómo el tratamiento de las campañas negativas se vuelve cada vez más duro en los últimos años: casi siempre terminan en muerte. Sin duda los espectadores llegan a empatizar con el sufrimiento de las víctimas.

Las piezas audiovisuales de alto impacto emocional contienen mayor cantidad de imágenes violentas explícitas que implícitas (gráfico 3). Con la finalidad de crear el mayor impacto emocional aparecen elementos como sangre, destrozos, actitudes agresivas por parte de los personajes, cuerpos sin vida, etc. En el caso de las campañas de 2013 o 2015, las imágenes de los cuerpos y otros elementos de connotación violenta se muestran en detalle y de forma explícita.

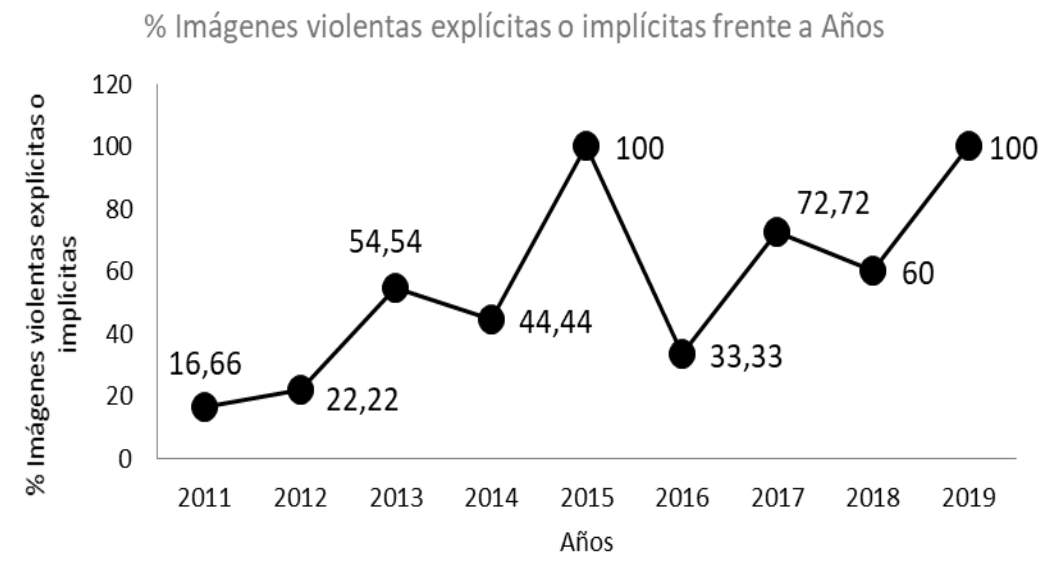

Gráfico 3. Porcentaje de imágenes implícitas o explicitas de las diferentes piezas audiovisuales de la DGT en el periodo 2011-2019

Fuente: Elaboración propia

En cuanto a la utilización de la imagen, se distinguen dos tipos de filtros dependiendo de la línea positiva o negativa que mantiene la campaña. En el caso de las campañas de carácter positivo, destaca un filtro más luminoso. Se utilizan imágenes agradables y armoniosas como por ejemplo luz del sol, naturaleza, caminos despejados, personajes reunidos, etc. Este tipo de campañas encierran imágenes amables como reuniones con seres queridos, llegada al destino, disfrute de las fiestas, etc. Por el contrario, las campañas de corte negativo suelen tener un filtro de imagen más oscuro y apagado. En estas suelen aparecer menos personajes y de modo general se muestra de forma 
explícita cómo sus vidas se truncan por sus malas decisiones o las de terceros. En este tipo de campañas predominan imágenes de vehículos destrozados, cuerpos tirados en la carretera, impactos violentos que se muestran de forma implícita o explícita, heridos, sangre, etc.

En cuanto al poder persuasivo de los spots (Gráfico 4) se observa un paralelismo con el nivel de dramatismo que encierran. Generalmente las piezas de mayor impacto emocional, imágenes explícitas de accidentes y de daños personales contienen un alto nivel de persuasión. De forma clara y explícita se insta al receptor a no cometer imprudencias mostrándole las consecuencias directas que se pueden generar. La mayoría de las piezas de corte negativo, terminan con frases directas de carácter imperativo, funcionando casi como una orden.
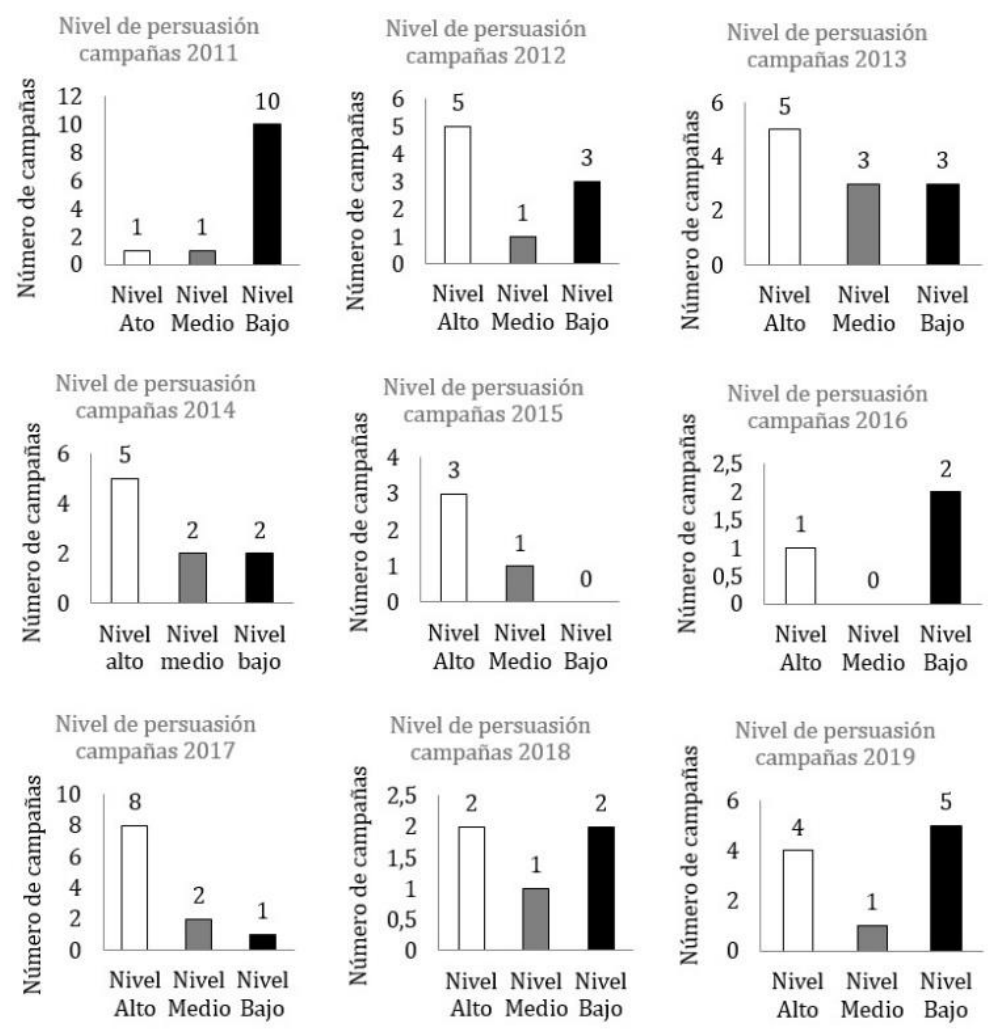

Gráfico 4. Niveles de persuasión de las diferentes piezas audiovisuales de la DGT en el periodo 2011-2019

Fuente: Elaboración propia

En las campañas de mayor dramatismo se detecta un mecanismo claro de causaefecto. Los personajes sufren las consecuencias de sus mismas imprudencias o las imprudencias de terceros. En este sentido, la Dirección General de Tráfico siempre ha sido muy directa en sus mensajes, mostrando la realidad sin filtros. De ahí el carácter 
Estrategias persuasivas y emocionales en las campañas audiovisuales de la DGT en el periodo 2011-2019

duro de gran parte de sus campañas audiovisuales. Ejemplos claros son las campañas "Tú eliges" de 2017 o "Saca tus drogas de la circulación" de 2014.

El factor escarmiento y responsabilidad del conductor prevalece en la mayoría de las campañas de corte negativo. Los relatos se sustentan en infracciones de todo tipo conducción bajo los efectos de alcohol y drogas, exceso de velocidad, distracciones...-, y las acciones que se muestran terminan en tragedia, casi siempre reflejada de forma explícita. Los relatos reflejan malas decisiones que no tienen solución una vez que se han tomado. Un ejemplo claro de este planteamiento son las campañas "Si sabes cómo acaba ¿por qué empezar?" (2012) o "Tú eliges" de 2017.

Se observa una intensificación de la línea negativa de las campañas audiovisuales en los últimos años. El carácter de las campañas audiovisuales de corte negativo presenta un endurecimiento destacado en los años 2015 y 2017 respectivamente, tanto a nivel visual como narrativo. A partir del año 2013 con el lanzamiento de la campaña de verano "Viajar es vivir", la DGT retoma la llamada "línea dura" mostrando imágenes explícitas y detalladas de cuerpos sin vida, sangre y heridas abiertas, elementos que suponen un gran impacto emocional. El mecanismo de sensibilización y concienciación en este tipo de campañas radica en provocar en el espectador un alto impacto emocional y conmoción, poniendo el foco en los aspectos dramáticos o trágicos que conlleva un accidente de tráfico. Así, la mayoría de estas campañas apelan a las emociones primarias como miedo, sorpresa, sufrimiento, dolor, pérdida o vacío. Este tipo de efectos se detectan tanto en los personajes que intervienen en el relato como también a nivel abstracto, buscando la empatía y la sensibilización del espectador. Los estrechos vínculos emocionales entre los personajes son importantes a la hora de entender el impacto que las campañas producen en el espectador. Redundan en los vínculos padres-hijos, parejas, amistades y compañeros. Todos estos roles sufren de forma indirecta las consecuencias de los accidentes. Los padres (sobre todo la figura de la madre) tienen un papel fundamental en mostrar el sufrimiento que provoca la pérdida de un ser querido. Los amigos están ligados más a las conductas irresponsables y a la necesidad de tomar decisiones que muchas veces no tienen vuelta atrás.

Los recursos sonoros intensifican el efecto del impacto emocional en el espectador, pudiendo alcanzar un gran protagonismo en los momentos dramáticos. Son redundantes los golpes de sonido, llantos, gritos, impactos sonoros, sirenas, sonidos de frenazos y claxon. Todos ellos aportan mayor intensidad y dramatismo. Los silencios funcionan de manera especial aludiendo siempre a la muerte de forma violenta y a las vidas truncadas. La perspectiva creativa y compleja de los relatos es el punto fuerte de la DGT. Muchas de las campañas encierran significados metafóricos o simbólicos, que constituyen maneras distintas de acercarse a la realidad. Se usa mucho la voz de los personajes una vez fallecidos que han sido víctimas de accidentes y de alguna manera se les da la posibilidad de concienciar a través de sus trágicos finales, ya sea a través de la narración o la imagen. Es el caso del protagonista de la campaña de 2013 "Viajar es vivir". 
Estrategias persuasivas y emocionales en las campañas audiovisuales de la DGT en el periodo 2011-2019

\section{DISCUSIÓN}

En el discurso audiovisual de la DGT a lo largo de la recopilación de las 74 piezas audiovisuales del periodo 2011-2019 predomina una línea negativa, que apuesta por campañas de alto impacto emocional. A pesar de la faceta agresiva de sus campañas, la intención de la DGT es la de crear conciencia y acercarse al espectador con mensajes realistas y sin filtros, para mostrar la realidad como es. Las campañas audiovisuales lanzadas entre los años 2011 y 2019 responden de manera fiel al plan de comunicación establecido por el Plan Estratégico de Seguridad Vial vigente, en cuanto a ejes temáticos, receptores del mensaje y ámbito de actuación.

Se comprueba la eficacia de los mecanismos de persuasión que la entidad utiliza en sus campañas. Se pone el foco en el respeto por la ley y por las normas para una convivencia positiva y en la necesidad de asegurar su cumplimiento. Es frecuente la persuasión de forma explícita a través de mensajes claros y directos que funcionan como órdenes (utilización de imágenes explicitas e implícitas en circunstancias de accidentes de tráfico de gravedad, que de forma generalizada terminan en muerte). Asimismo, se manifiesta también la utilización de un enorme abanico de emociones del ser humano tanto en su dimensión negativa como positiva: en las campañas de perspectiva positiva predominan las emociones de alegría, amor, optimismo, esperanza, bienestar. En las campañas de corte negativo, son redundantes el sufrimiento, el miedo, la pérdida, el vacío, la culpabilidad y la agresividad.

\section{CONCLUSIONES}

En cuanto a las principales hipótesis que se han planteado en el inicio es preciso atender a su cumplimiento o no:

La hipótesis $1(\mathrm{H} 1)$ se cumple ya que se ha podido comprobar un cambio de carácter a partir del año 2013. Se observa una clara transformación de discurso hacia una línea negativa mucho más potente y también más abundante.

La hipótesis 2 (H2) se cumple ya que desde el Plan Estratégico de Seguridad Vial se apuesta por la transmisión de valores y aprendizaje social. Tanto las campañas de corte positivo como las de corte negativo encierran un aprendizaje que casi siempre se muestra de forma explícita al final mediante una frase concisa. Las campañas muestran una recompensa por las buenas conductas -reuniones familiares, de las vacaciones, fiestas familiares-, y trágicas consecuencias para las malas conductas -muerte, pérdida, culpa-. 
Estrategias persuasivas y emocionales en las campañas audiovisuales de la DGT en el periodo 2011-2019

\section{REFERENCIAS}

Alvarado López, M. C. (2010). La Publicidad Social: una modalidad emergente de comunicación (Tesis doctoral). Universidad Complutense de Madrid, Madrid. http://eprints.ucm.es/11522/

Benavides Delgado, J. (1997). Lenguaje Publicitario: hacia un estudio del lenguaje en los medios. Madrid, España: Síntesis.

Cortés Gonzáles, A. (2008). Conceptualización de la publicidad institucional en su dimensión socializadora y educativa. Espacios Públicos, 11(22), 226-237. http://www.redalyc.org/pdf/676/67602212.pdf

Dirección General de Tráfico. (2011). Estrategia de Seguridad Vial 2011-2020. (no 1). http://www.dgt.es/es/la-dgt/centro-dedocumentacion/biblioteca/publicacioneselectronicas/publicaciones/2011/estrategia-deseguridad vial-2011-2020.shtml

Dirección General de Tráfico. (2018). En 2017, 1.200 fallecidos. Tráfico y Seguridad Vial. 239, portada. http://revista.dgt.es/es/noticias/nacional/2018/01ENERO/0103Presentacion-balance- accidentes-2017.shtml

Dirección General de Tráfico. (2011-2016). Siniestralidad Vial 9(14). http://publicacionesoficiales.boe.es/

Dirección General de Tráfico (2018). Misión, visión y objetivos. España: Dgt.es. http://www.dgt.es/es/la-dgt/objetivos-y-competencias/

Dirección General de Tráfico (2018). Historia. España: Dgt.es. http://www.dgt.es/es/ladgt/quienes-somos/historia/

Dirección General de Tráfico. Campañas. España: Dgt.es. http://www.dgt.es/es/indexcampana.shtml 2

Dirección General de Tráfico (2018). DGT.es. España: YouTube. https://www.youtube.com/user/publicidaddgt3

Feliu Albaladejo, A. (2004). Publicidad institucional y publicidad electoral. En Mínguez Arranz, N. y Villagra García, N. (Coord.) La comunicación: nuevos discursos y perspectivas (509-516). Madrid, España: Edipo.

García López, M. (2001). Publicidad Institucional: el Estado anunciante. Málaga, España: Universidad de Málaga. Servicio de Publicaciones e Intercambio. 
Estrategias persuasivas y emocionales en las campañas audiovisuales de la DGT en el periodo 2011-2019

Gómez García, Y. (2016). La eficacia de la publicidad emocional y racional: análisis de las campañas de la Dirección General de Tráfico. (Trabajo Fin de Máster). Universidad de León. León. https://buleria.unileon.es/bitstream/handle/10612/5482/71464244R GMIM Julio16.pdf

López Vázquez, B. (2007). Publicidad emocional. Estrategias creativas. Madrid, España: Eisec Editorial.

Martínez Rodrigo, E., y Segura García, R. (2012). Música y emociones en campañas institucionales. El caso de la DGT española (1964-1983). Revista de Comunicación Vivat Academia, (117E), 643-655. https://doi.org/10.15178/va.2011.117E.643-655

Martínez Rodrigo, E., y Segura García, R. (2013). El discurso emocional en la publicidad audiovisual de la DGT. Estudios sobre el Mensaje Periodístico, 19, 863-872. http://revistas.ucm.es/index.php/ESMP/article/view/42169

Ministerio del Interior (2017, 27 de abril). Tú Eliges [Archivo de video]. https://www.youtube.com/user/interiorgob4

Moragas Spá, M. (2005). Publicidad institucional, comunicación y civismo. Los $\begin{array}{llll}\text { monográficos de } & \text { B.MM, } & \text { (6), } & \text { 22-77. }\end{array}$ http://www.publicacions.bcn.es/b mm/ebmm civisme/072-077.pdf

Radio Televisión Española (2017d, 18 de diciembre). La mortalidad por accidentes de tráfico re-punta en 2017 por segundo año consecutivo. España: Rtve.es. http://www.rtve.es/noticias/20171218/mortalidad-accidentes-trafico-repunta-2017segundo-ano-consecutivo/1648003.shtml

Rey, J., y Pineda Cachero, A. (2009). Propaganda y publicidad institucional: Algunas consideraciones teóricas. Questiones publicitarias, 1 ( $n^{\circ}$ Especial), 9-32. https://idus.us.es/xmlui/bitstream/handle/11441/13057/file 1.pdf?sequence=1\&isAllow $\underline{e d=y}$

Segura García, R. (2014). Personajes y discurso emocional en las campañas de la DGT. Análisis de los Spots de 2007-2011. Historia y Comunicación Social, 19 (no 2 febrero), 355-363. https://dialnet.unirioja.es/servlet/articulo?codigo=5040071

Segura García, R. (2015). Evolución y efectividad de los spots de la DGT. Revista Opción, 31(3), 1180-1200. http://www.redalyc.org/html/310/31045567062/

Segura García, R. (2017). Retórica de las emociones en la Publicidad Audiovisual de la DGT. Análisis de los spots de 1962 a 2013. (Tesis Doctoral). Universidad de Granada. Granada. https://hera.ugr.es/tesisugr/26518077.pdf

Vieira García, C. (2014). Uso y Eficacia del Miedo como Factor Persuasivo en las Campañas Institucionales de la Dirección General de Tráfico. (Trabajo Fin de Grado).

Revista de Comunicación y Salud. 2022, Vol. 12, 1-20 
Estrategias persuasivas y emocionales en las campañas audiovisuales de la DGT en el periodo 2011-2019

\author{
Universidad de Málaga. Málaga. \\ https://riuma.uma.es/xmlui/bitstream/handle/10630/11384/TFG\%20CRISBEL\%20VIEI \\ RA\%20\%28DGT\%29.pdf? sequence $=1$ \&isAllowed $=y$
}

\begin{abstract}
AUTORES
Iulia Mihaela Marinescu

Currículum vitae reducido: Iulia Maihaela Marinescu es Licenciada en Periodismo por la Universidad de Zaragoza y master en Comunicación Audiovisual para la Era Digital por la Universidad Complutense de Madrid. Comenzó su experiencia laboral con una beca en el Área de Comunicación Institucional para la Asociación Española de Investigación de la Comunicación (AE-IC). A finales de 2019 se incorporó al Grupo de Comunicación La COMARCA de Alcañiz, (Promotora Cultural del Bajo Aragón) donde profesa activamente en el periodismo local, al frente de los informativos 'Hora 14 Bajo Aragón'. Le interesa el periodismo cercano y tiene especial inclinación por el área social y cultural.
\end{abstract}

Orcid ID: https://orcid.org/0000-0002-9480-0476

\title{
Guillermo Mejías Martínez
}

Currículum vitae reducido: Guillermo Mejías Martínez es doctor en neurofisiología por la Universidad Complutense de Madrid y master en Comunicación Audiovisual por la misma universidad. Sus áreas de investigación incluyen el estudio neurológico de los fenómenos de la neurocomunicación y neurocognición, con publicaciones en revistas internacionales como Brain Stimulation.

Orcid ID: https://orcid.org/0000-0003-4800-3852

\section{Antonia Isabel Nogales-Bocio}

Currículum vitae reducido Antonia Isabel Nogales-Bocio es profesora Ayudante Doctora (Acreditada Contratada Doctora) del Área de Comunicación Audiovisual y Publicidad de la Universidad de Zaragoza. Vicepresidenta del Laboratorio de Estudios en Comunicación y miembro de los grupos de investigación en Comunicación e Información Digital (GICID); Estructura, Historia y Contenidos de la Comunicación (GREHCCO) y Social Media y Educación Mediática inclusiva y ubicua (SMEMIU). Ha publicado artículos en revistas de impacto y es autora de trabajos en editoriales de prestigio relacionados con sus principales líneas de investigación: el estudio estructural de la comunicación, la Historia del Periodismo Español y el análisis crítico del discurso.

Orcid ID: https://orcid.org/0000-0003-0050-6979 